\title{
Making Informed Decisions: EXPLORE Engineering Design Program
}

\author{
Holly Algra, Libby Osgood, Amanda MacLean, and Clifton Johnston \\ Dalhousie University \\ Holly.Algra@dal.ca, LibbyOsgood@dal.ca, MacleanAm1@gmail.com,Clifton.Johnston@dal.ca
}

\begin{abstract}
Decisions must be made at the age of 16 and 17 that can have long-lasting effects. High school students are asked to select a specific degree, a university, and sometimes even a specific discipline with very little basis for making the decision. The EXPLORE program was piloted at Dalhousie University in the Summer of 2014 and 2015 to help girls in high school make an informed decision about whether or not to pursue an engineering degree.

10 students signed up each summer to EXPLORE engineering design in a compressed 2-week schedule where they participated in 3 short design projects, culminating in a major project for a client from the community. The girls developed documentation, presentation, leadership, and teamwork skills. They learned CAD software, practiced 3-D printing, and were exposed to robotic programming. They built and tested a design for a community partner and defended the design to a room of people. The students were introduced to visualization techniques, the engineering design process, $\log$ books, and other essential components that they would only otherwise encounter during their first year in an engineering program. This paper will document the elements of the course that help the girls make an informed decision about whether or not to pursue engineering from two perspectives: the instructors' and the student's.
\end{abstract}

Keywords: Engineering Design, First Year Design, Recruitment Tools, High School Outreach, Engineering Outreach

\section{INTRODUCTION}

EXPLORE is a two-week course offered at Dalhousie University during the beginning of summer for girls who have finished grades 10 and 11 . The days are fully scheduled and consist of hands on design projects, introductions to types of engineering work through the use of mentors and guest speakers, and use of engineering tools. The course can be used as credit for the first year design course typically taken in the first semester of an engineering degree. The objective of the course is to expose female high school students who are considering engineering to the different disciplines, help them make a decision regarding engineering in their future, and introduce them to role models in the profession. EXPLORE is, in part, a recruitment tool for females into engineering, but is more importantly a tool to allow the participants to make an informed decision about what direction they should pursue in university. The course has been running for two years, with 10 participants each summer. This paper outlines the differences between this course and the first year design course, as well as the objectives the course aims to achieve.

As of December, 2014, the national percentage of newly licensed engineers who are women was $17 \%$, which Engineers Canada has committed to increase to $30 \%$ by 2030 [6]. There are several recommendations for increasing the retention of females in computer science and engineering degrees. Providing mentors in specific disciplines and peer support accessible to the students encourage persistence and success in their studies [3][4]. Personal encouragement while still in high school also have shown to be a major influence in the decision for females to go into the sciences [8]. EXPLORE, while a recruitment tool, attempts to provide a realistic view of what engineering entails through practice, trial, and mentors.

The EXPLORE program offers credit to the participants in a pass/fail manner. Many medical schools have changed from letter or numerical grades to a pass/fail system [9]. The move towards a pass/fail system is encouraged to increase psychological well-being and to promote team learning within the course in part by limiting the competition [2]. Its supporters state that it moves the emphasis from exams and towards genuine learning [12]. Concerns with a pass/fail system include reduced scores on standardized testing, but this has not been observed to be statistically different between those who have letter grades and those who do not [10].

While it is shown that grades in high school are a significant predictor of further educational success [7], there are other factors which allow students to fit into particular schools and programs. An obstacle faced by students can be a lack of knowledge about college, which 
can lead to unknown expectations of the processes and experiences they will encounter in university [5]. Postsecondary institutions such as New York University, Harvard, Brown University, and many others are now offering both non-credit and credit pre-college courses to high school students. These courses help the students to understand and choose their desired program, develop their skills, become familiar with the grounds and university system, meet faculty, and create a community of peer support. These elements can later help them in their selection of and continuation in their university path.

\section{PARTICIPANTS}

EXPLORE has run for two consecutive summers. Each time has had 10 participants, all from the province of Nova Scotia and most from the Halifax region.

Several observations were made of the participants from the past two years. The participants in the course are only female as this is a recruitment technique to encourage women to continue in engineering. One of the participants who later continued in engineering stated that there were less ego challenges among the teams, which she believed was due to the gender makeup of the groups. This mirrors literature which finds that women have lower confidence in their skills than their equal male counterparts [1][11]. As well, it was noted that the two years were very quiet compared to mixed groups of first year students.

The subset of students who apply to the program is unique in that they represent high functioning students who are willing to both pay for the program and give up two weeks of their summer. This resulted in an unusual grouping who seemed better prepared for project documentation than a typical first year student. It was observed that the majority of the participants also started the program with a higher level of learning in areas such as the use of Microsoft Word, Powerpoint and resulting presentations, Excel, and even their levels of English.

There was little ethnic diversity in the group, as none of the participants identified as being an international student. This results in a very different group makeup than is seen in many of the first year design groups due to the common first language and cultural practices.

\section{DIFFERENCES BETWEEN EXPLORE AND DESIGN 1}

While it is shorter, the EXPLORE program offers several aspects that the first year design course does not. Due to the fact that there is a smaller class size, traditionally 10 versus 400 , coding and robots were able to be integrated into the curriculum of EXPLORE. Design
1 traditionally only has a single, theoretical design project, whereas EXPLORE participants are given 3, with at least one of them for a community client. Hands-on building of prototypes of design projects is included, and can be increased in complexity than what is possible in a larger class. The focus on hands-on design projects tailored to specific clients also increases the client relations that the participants must navigate.

The participants are introduced to women speakers from all disciplines of engineering who describe both their work and their lifestyle. Current students are also employed as mentors at lunch so that the participants can ask questions about the school work and the process of applying and picking a discipline. The class is allencompassing, which allows the participants to focus solely on the course, a luxury not afforded when the design course is taken in the fall as a normal course load. This allows EXPLORE and the design projects to be the centre of focus, and allows the design process to be emphasized throughout each day.

One notable difference between EXPLORE and Engineering Design 1 is the exposure to time management skills. The schedule of EXPLORE is over a two-week period, and while students must complete the design during this short period, students are enrolled in only one course. The average first year engineering student is enrolled in six courses, which has a significant impact on the way students manage their time for Design 1 projects in order to meet the assigned deadlines. Design 1 is an engineering student's first introduction to project-based learning, and allows students to navigate through managing a four-month project and producing a final product on time. Though EXPLORE does require students to complete a design project, the final report is the student's only priority. Juggling six courses means final reports are often due at the same time as other important deadlines students may have in their other courses. The stresses associated with this are an important opportunity to teach students valuable skills they will carry with them throughout their degree and future career. However, students who took EXPLORE still have the opportunity to develop their time management skills with five courses in their first semester instead of six, reducing the stress in their inaugural semester.

Another important skill that students are required to develop in Design 1 is conflict management. One of the largest challenges students face throughout their engineering careers is learning how to effectively work in teams, and how to resolve conflicts with their teammates. Students who enroll in the EXPLORE program have chosen to give up two weeks of their summer holiday to spend in a classroom. These students tend to be highly focused and motivated. As such, the most common team conflict students face in EXPLORE is learning to share leadership responsibilities. Additionally, without the stress 
of a final grade as the course is pass/fail, students in EXPLORE experience less conflict amongst group mates than students in Design 1, such as teammates who do not attend class, miss group meetings, do not complete work on time, or drop the course mid semester. Groups are composed of students with a range of skill levels, grade expectations, and amount of free-time. Design 1 gives students the opportunity to develop these interpersonal skills to resolve conflicts within their teams and eventually apply these skills in industry. Students in the EXPLORE program have a similar opportunity to develop these skills but perhaps experience less conflict without the risk of receiving a poor grade and the homogeneity of the team composition.

The final difference between the two programs concerns the development of CAD, sketching, and visualization skills. While EXPLORE emphasizes the development of design skills and creates the environment for students to practice graphical communication skills through the application to their project, the Design 1 course typically has spent more time on the development of the skill before application to their project. Students in Design 1 are assessed on their ability to visualize and sketch isometric and orthographic views, learn how tolerancing is applied in industry, and develop more indepth CAD skills through regular assignments over a longer period. Arguably, the shift in focus of the EXPLORE program towards design and away from pure skill development addresses the needs of more students across the engineering disciplines.

\section{DISCUSSION}

The EXPLORE program offers high school students who are curious about engineering the freedom to participate in an engineering course without the commitment of an entire semester of six courses. Because the students are participating in a two-week, educational program during their summer break, the structure of the course is different than that of a standard design course. The intensive 8-hour days of instruction do not allow time for homework or assignments, necessitating the students to be self-motivated to complete the reports and presentation preparation during the allotted time during the day. The type of student who would give up two weeks of their summer in order to confirm their selection for university, comes to the course already skilled, with a determined attitude. Very little time is required to prepare these students on how to do a presentation, make slides, use Excel to perform analyses, or format a document. Unlike teaching a course where students have a range of abilities and motivations, the instructions are provided once to the EXPLORE students, and they begin working immediately with very little follow-up required. This allows the students to accomplish much more than if there were a range of abilities in the course, where topics must be repeated, reviewed, and possibly start from an earlier place of knowledge. Grades are not required to motivate the students, and instead, the focus can be on what is correct as opposed to what is the rubric, or perhaps more motivating: what benefits the client most.

The course credit for Design 1 was provided for participants who successfully met certain requirements from EXPLORE, in order to encourage participation in the EXPLORE program and to recruit high-achieving students to Dalhousie University. With their attention focused on one course, the EXPLORE students can fully learn on the material, practice the design process on three projects, and practice teamwork holistically, in a more realistic environment to the workplace than the student model of finding times to meet after classes or on weekends. There has been a ratio of five students per instructor, providing high quality and quantity time for evaluation, help, and feedback. Rather than learning how to practice $\mathrm{CAD}$ on a simulated design challenge, EXPLORE students work with a real client, learn how to ask the right questions, get frustrated with the ambiguity of problem definition, experience the complex and changing client requirements, and feel the satisfaction of prototyping a solution to satisfy the client. This more realistic environment can produce functional and education results in the short time frame because of the low student to instructor ratio and high ability of the students.

While there is a lack of diversity in gender, abilities, and motivation, the students have different personalities, are together constantly for two weeks, and the clash for control can create situations for interpersonal development. The course provides an experience more similar to industry (albeit a difference in diversity), which may leave students surprised when they encounter an unmotivated student in their first team engineering project.

It would be interesting to follow up with the students to determine if they approached courses in grade 11 or 12 differently than the previous year, having taken the EXPLORE program. It is conceivable that this glimpse into the requirements of university helped hone the students to focus on what is important about their classes. Although already serious students, perhaps they paid more attention to the learning as opposed to the grade, having seen the application for the knowledge and not merely the quantitative assessment.

\section{CONCLUSION}

While the response from past participants, parents, mentors, and clients has been positive, program effectiveness cannot yet be assessed as the participants entering grade 11 will not enter university for two years. 
Past participants have requested EXPLORE instructors to be references on university applications and scholarships for engineering programs, which is encouraging. True evaluation will only begin to occur in 2019 , to see how many of the initial students going into grade 12 after the first offering completed an engineering degree. If the program were not to be offered again, it will be 2017 until all of the nineteen students graduate from high school, and 2021 until they graduate from university (2022 if they participate in co-op). While recruitment into engineering fields is an objective of the course, it would not be considered failure if the course helps a student to decide they do not want to pursue engineering. Ultimately, this potentially saved a year of being in the 'wrong' field, because they were able to make an informed decision.

The main objective of the course is for exposure of the engineering fields, help students to make a decision regarding possible disciplines, and meet role models. Twenty students produced six successful designs for the Make-A-Wish foundation and a member of the blind and visually impaired community in Halifax. They made an impact in the community through these service-learning projects, learned graphical communication, improved technical writing skills, presented to a technical audience, and practiced these skills through three design projects. If they go to Dalhousie for engineering, they will be familiar with the campus, recognize some of the students as former EXPLORE role models, and have connections to the Engineers Nova Scotia office for future professional development.

\section{References}

[1] K. Arnold, Academically Talented Women in the 1980's: The Illinois Valedictorian Project, K. Hulbert \&. E. Schuster, Eds., San Francisco, CA: Jossey-Bass, 1993.

[2] R. A. Bloodgood, J. G. Short and J. M. Jackson, "A Change to Pass/Fail Gradin in the First Two Years at One Medical School Results in Improved Psychological Well-Being," Academic Medicine, pp. 655-662, 2009.

[3] J. Cohoon, "Towards Improving Female retention in the Computer Science Major," Communications of the ACM, vol. 44, no. 5, pp. 108-114, 2001.
[4] J. Cuny and W. Aspray, "Recruitment and Retention of Women Graduate Students in Computer Science and Engineering: Results of a workshop Organized by the Computing Research Asociation," SIGCSE Bulletin, pp. 168174, 2000.

[5] J. M. Dennis, J. S. Phinney and L. I. Chuateco, "The Role of Motivation, Parental Support, and Peer support in the Academic Success of Ethnic Minority First-Generation College Students," Journal of College Student Development, pp. 223-236, 2005.

[6] Engineers Canada, "Reaching 30 by 30 - Promising Practices for Increasing Diversity \& Inclusion in Engineering," Engineers Canada, Ottawa. Available as of May 9, 2016 from https://www.engineerscanada.ca/sites/default/files/30by30en.pdf.

[7] M. T. French, J. F. Homer, I. Popovici and P. K. Robins, "What you do in High School Matters: High School GPA, Education Attainment and Labor Market Earnings as a Young Adult," Eastern Economic Journal, pp. 370-386, 2015.

[8] J. Margolis, A. Fisher and F. Miller, "The Anatomy of Interest: Women in Undergraduate Computer Science," Women's Studies Quarterly, p. Spring/Summer, 2000.

[9] L. S. Robins, J. C. Fantone, M. S. Oh, G. L. Alexander, M. Shlafer and W. K. Davis, "The Effect of Pass/Fail Grading and Weekly Quizzes on First-Year Student's Performances and Satisfaction," Academic Medicine, pp. 327-329, 1995.

[10] D. E. Rohe, P. A. Barrier, M. M. Clark, D. A. Cook, K. S. Vickers and P. A. Decker, "The Benefits of Pass-Fail Grading on Stress, Mood, and Group Cohesion in Medical Students," Mayo Clinic Proceedings, pp. 1443-1448, 2006.

[11] L. J. Sax, "Predicting Gender and Major-Field Differences in Mathematical Self-Concept During College," Journal of Women and Minorities in Science and Engineering, pp. 291307, 1994.

[12] J. Weller, "The Effect of Pass/Fail Grading and Weekly Quizzes on First-year Student'," Journal of Research and Development in Education, pp. 39-45, 1983 